\title{
How natural is modern agriculture?
}

\author{
Neal K. Van Alfen
}

A griculture is an invention just as automobiles, airplanes and computers are. As a species, humans have been very skilled at manipulating the natural resources of this planet to meet our needs. Agriculture is one of the oldest of our inventions; weapons and clothing are probably the only ones that preceded agriculture in our assemblage of discoveries. Agriculture is certainly our most important invention, since without it the constant search for food would have precluded other developments.

The speed of discovery of new tools is rapidly accelerating, sometimes faster than we can emotionally adapt to them. Some changes are easier for us to accept. There has been little opposition to communication or transportation developments, for example. Automobiles have been the primary focus of transportation planning in the United States during the second half of the 20th century despite the enormous environmental costs associated with their use. We are also willing to accept significant personal danger when we drive automobiles, yet there are few organized protests against them. In the personal risk/benefit analysis conducted by most people, we accept the problems of using the automobile because of its advantages. Most of us are well informed about issues related to automobiles, so we feel that we can make reasonable judgments about using them.

A century ago almost everyone was intimately familiar with agriculture. Today most people have little accurate knowledge about how crops and domestic animals are raised. The controversy about agricultural biotechnology is taking place within this context of general ignorance. In recent years, modern agriculture has been charac-

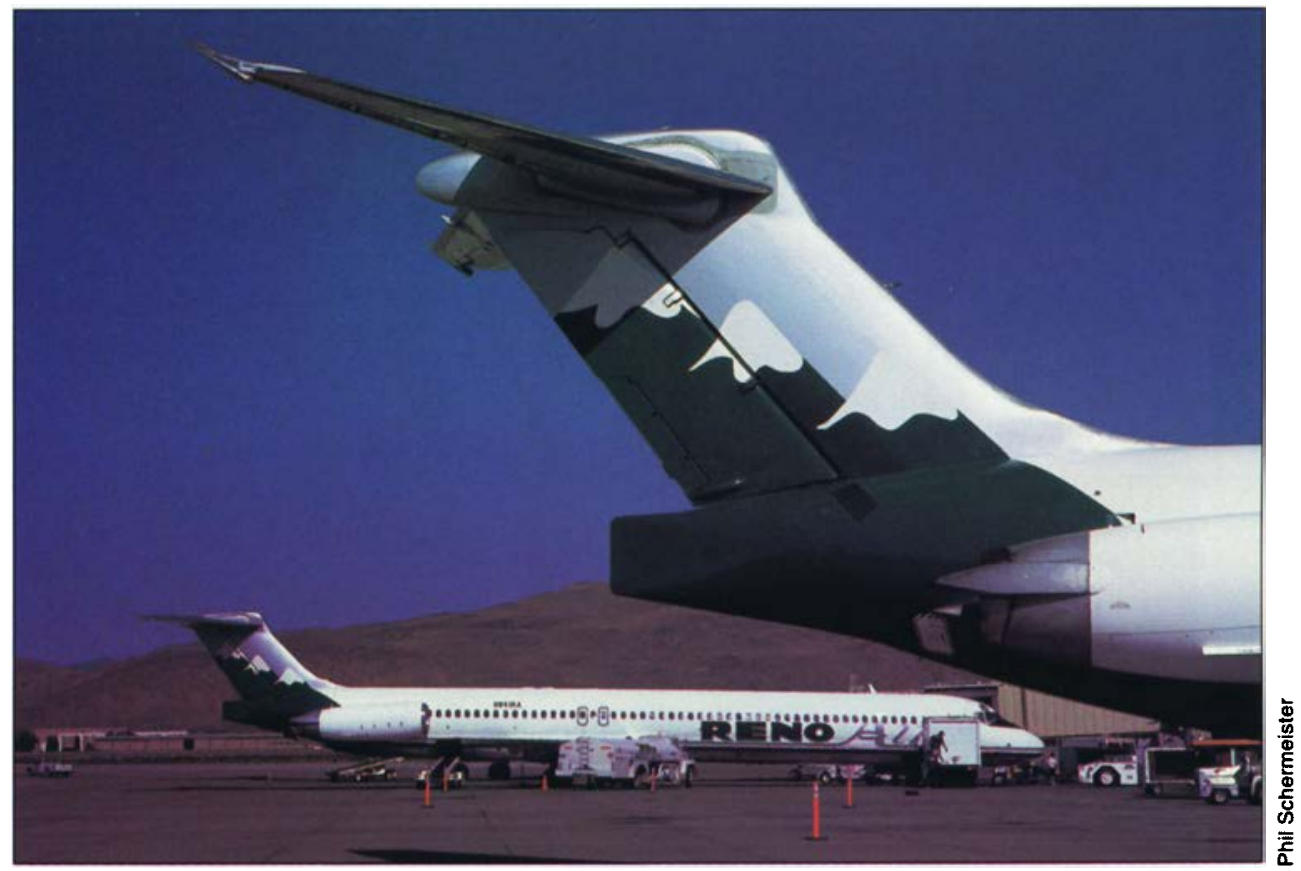

Like the airplane, agriculture is an invention. While many people are familiar with the history of the airplane, few today know very much about how food and fiber are produced.

terized by critics as "unnatural" while that of a century ago is sanctified as "natural." Such value judgments are often based upon mythology rather than fact. UC scientists have an obvious educational challenge to provide sufficient information so that people can make informed personal decisions regarding agriculture, just as they recognize the need for continuously advancing transportation systems.

Natural is usually assumed to be good whereas unnatural is assumed to be bad. Unfortunately life does not provide such simple alternatives. Natural is often characterized as being that which operates independent of humans. Agriculture in this context is natural since it is not a unique discovery of humans.

Ants developed the equivalent of dairy herd management at least 50 million years ago (Holldobler and Wilson 1990). Certain ants husband aphids, much as we do dairy herds, to collect the honeydew they secrete. The aphids maintained by ants are morphologically and behaviorally different from other aphids, indicating that a process of selection has occurred, much as livestock domesticated by humans are different from their wild progenitors. Other ants cultivate fungi for food, maintaining specific clones of the fungus, preparing a substrate for its growth, fertilizing the growing fungus, weeding out contaminating fungi, and protecting the fungus using antibiotics that the ants secrete (Holldobler and Wilson 1990). This is agriculture as practiced by humankind today.

The success of humans on our planet is largely due to our being par- 


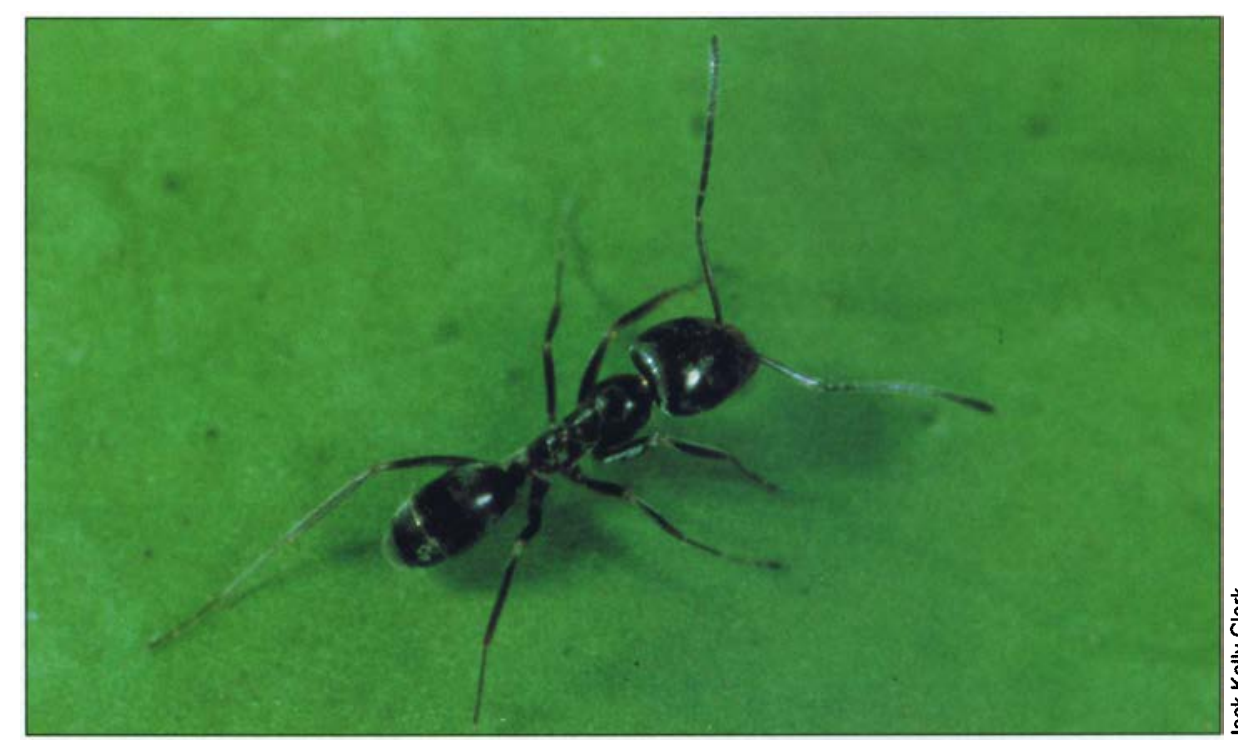

Humans are not the only species on Earth that practices agriculture. Ants have been herding aphids to collect their honeydew for at least $\mathbf{5 0}$ million years.

ticularly skilled at adapting other life forms for our use. Just as ants select and maintain specific clones of fungi, early humans found that they could influence the evolution of other species, such as the progenitors of most of our important crop plants and domestic animals. Corn, the most widely cultivated crop, does not exist in natural communities. This crop, like most others, is a creation of humankind.

One of the issues facing modern agriculture is the perception that scientists today are doing things that are fundamentally unnatural and risky. Our ability to sustain the numbers of people who live on Earth is only possible because we, like ants, have learned how to influence the evolution of other life forms. The development of methods, even in prehistoric times, for directing evolution is one of the major reasons our species has been so successful. The diversity of plants and

\section{Our ability to sustain the numbers of people who live on Earth is only possible because we, like ants, have learned how to influence the evolution of other life forms.}

animals that we have domesticated is unprecedented, and our methods of influencing their growth and evolution are not found in the life histories of other dominant species. We learned how to make sexual crosses between sexually incompatible species, how to mutate and select new forms, how to provide specific nutrients to a wide array of other organisms to enhance their growth, how to protect against pests, and how to store food for long periods of time. Recently we have learned how to identify specific genes in one species and move these into the genomes of other species. This most recent discovery is the basis of agricultural biotechnology. It is a natural ex-

The movement of genes between different organisms is troubling and unnatural to some people. Just as agriculture is not unique to humans, directed gene movement also preceded us. Exchange of genes appears to have been common in the evolution of life on this planet. Life as we know it would not exist had it not been for this "unnatural" movement of genes. Within each of our cells are the remnants of bacteria that exchanged genes with the nuclei of these cells. Such movement of genes between different organisms has occurred many times in evolutionary history, and will no doubt continue. Our first success in mimicking this gene transfer in crop plants was based upon a naturally tension of our previous discoveries. evolved gene-exchange mechanism of Agrobacterium tumefaciens. This bacterium injects part of its DNA into plant cells, changing the plant into an ideal growth environment for the bacterium. The first scientists to move genes into plants used this bacterial DNA because it was naturally adapted to insert its DNA into plant cells. Is our use of this natural mechanism to move genes into plants any more natural or unnatural than directing the evolution of corn?

One of the characteristics of humankind is that we are curious and inventive. We walk on the moon, we explore the depths of the oceans, we communicate instantaneously across oceans, and we can fly faster than any bird. None of this is natural. Unlike many of the activities that stem from our curiosity, agriculture is absolutely necessary to maintain our growing population. We can't stop progress in agricultural technology if we hope to preserve those activities that define modern humankind. Many people are excited about the prospect that modern agricultural technology will significantly reduce the environmental costs associated with traditional agriculture and provide simple and inexpensive means to address the health problems of millions of undernourished people. There are risks and benefits associated with almost every choice humans make. A challenge to agriculturists and researchers is to help the general public become aware that agriculture is simultaneously natural and unnatural and that both aspects are essential. In raising and eating our food, as in manufacturing and riding in automobiles, there are risks and benefits associated with each alternative approach.

N.K. Van Alfen is Dean, College of Agricultural and Environmental Sciences, UC Davis.

\section{Reference}

Holldobler B, Wilson EO. 1990. The Ants. Cambridge, MA: Belknap Press. 732 p. 